\title{
ENTRE OUTRAS ESTRATÉGIAS DE CONTROLE E DOMINAÇÃO: Estado, agricultura e colonização na Amazônia Oitocentista
}

\author{
Francivaldo Alves Nunes*
}

\begin{abstract}
RESUMO: Este artigo propõe analisar a relação entre os discursos construídos em torno da agricultura e colonização, caracterizados pela moralização da sociedade e a atuação do Estado imperial. Baseado em relatórios governamentais e de expedições, tentamos demonstrar como esses valores, associados à atividade agrícola, exigiram do Estado um desempenho não apenas de manutenção da ordem, mas como instituição promotora de políticas que elevassem os hábitos das populações na Amazônia. A compreensão é que não se tratava de um Estado que se afirmava apenas pelo uso das forças militares, mas que levasse a autoridade do governo ao interior das províncias do Pará e Amazonas, através de ações revestidas de um discurso de promoção da ordem, da modernidade e da civilização.
\end{abstract}

PALAVRAS-CHAVE: Estado; Amazônia; Século XIX.

\section{Among other strategies of control and domination: state, agriculture and settlement in the nineteenth century Amazon}

ABSTRACT: This article aims to analyze the relationship between the discourse built around agriculture and colonization, characterized by the moralization of society under the rule of the imperial state. Based on government reports and expeditions, we try to show how these values, associated with agricultural activity, required the State a performance not only to maintain order, but as institution promoting social politics that would elevate the habits of people in the Amazon. The understanding is that it was not a State which claimed only by using military forces, but took its authority to the interior of the provinces of Para and Amazonas by using a discourse of order promotion, modernity and civilization.

KEYWORDS: State; Amazon; Nineteenth century.

\section{Entre otras estrategias de control y dominación: Estado, agricultura y colonización en la Amazonia decimonónica}

RESUMEN: Este artículo tiene como objetivo analizar la relación entre el discurso sobre la agricultura y la colonización, que se caracteriza por la moralización de la sociedad y el papel del estado imperial. A partir de los informes del gobierno y expediciones, tratamos de mostrar cómo estos valores, asociados con la actividad agrícola, exigieron del Estado una actuación no sólo para mantener el orden, sino como institución que promueve políticas que elevarían los hábitos de las personas en la Amazonía. El entendimiento era que el Estado debía se afirmar no solo por la fuerza militar, pero que llevara la autoridad del gobierno al interior de las provincias de Pará y Amazonas, a través de acciones amparadas por un discurso de promoción del orden, de la modernidad y la civilización.

PALABRAS CLAVE: Estado; Amazon, Siglo XIX.

\footnotetext{
*Doutor em História Social pela Universidade Federal Fluminense e professor da Faculdade de História (Campus Ananindeua) e do Programa de Pós-Graduação em História Social da Amazônia (Campus de Belém) - FH/PPGHIST/UFPA. E-mail: francivaldonunes@yahoo.com.br.
} 


\title{
Da coerção ao convencimento e a compreensão de ordem legitimada
}

\begin{abstract}
Na fértil província do Pará, onde a natureza dá a todos com espontânea superabundância tudo o que é preciso para viver, o trabalho é tido por essas classes como um constrangimento desnecessário, e intolerável. O nosso tapuio, que ergue a sua barraca, ou o palheiro à margem de qualquer desses rios e lagos variadamente piscosos, rodeados de matas e florestas virgens, ubérrimas de frutos, drogas, e especiarias, abundantes de uma infinita variedade de caça em quadrúpedes e voláteis, vive descansando e descuidoso no seio da abundância; e se estas circunstâncias o dispensam do trabalho voluntário, com que repugnância, e odiosidade se não prestará ele ao trabalho obrigatório? E ainda mais quando a obrigação do trabalho pela lei tem sido tão geralmente convertida em especulação e vexação pelo abuso? ${ }^{1}$
\end{abstract}

No pronunciamento à Assembléia Legislativa do Grão-Pará, de $1^{\circ}$ de outubro de 1854, o conselheiro Jerônimo Francisco Coelho, então presidente da província, defendia as atuações a serem tomadas pelo governo imperial na Amazônia, não mais pautada no uso de armas e na "perseguição" as populações distribuídas pelo interior da região, pois era assim que considerava as práticas de parte das autoridades provinciais com a justificativa de combater possíveis revoltas. No caso, fazia referência direta à instituição dos Corpos de Trabalhadores. Divididos em companhias ligadas às diversas localidades, estes deveriam ser formados a partir do recrutamento de índios, mestiços e pretos que não fossem escravos e não tivessem propriedade ou estabelecimento a que se aplicasse a alguma atividade produtiva. A mão-de-obra obtida através desses alistamentos compulsórios seria destinada ao trabalho nas obras públicas e nos serviços particulares (FULLER, 1999, p. 5).

As atuações dos Corpos de Trabalhadores, enquanto ações de combate ao que se identificava como "vagabundos e homens ociosos" sofriam críticas do governo provincial por ter se convertido em instrumento de abuso dos comandantes militares e outras autoridades locais. Acrescenta o conselheiro Jerônimo Coelho que, se num primeiro momento o pensamento que havia justificado a criação dos Corpos de Trabalhadores estava associado à moralidade e a ordem, tomou com alguns anos um caráter de abuso, que os converteu em meios de ganância e servidão. ${ }^{2}$

O pretexto de se arregimentar trabalhadores para os serviços públicos conduziu os comandantes a utilizar os indivíduos recrutados nos serviços de beneficiamento de propriedades suas e de seus correligionários. Nesse caso, a lei que devia acabar com o que se convencionava chamar de "vida licenciosa e vagabunda", gerava uma "vida opressiva e degradante", o que nas palavras de Jerônimo Coelho, não era mais compatível com os novos rumos que o país decidira tomar. ${ }^{3}$ Ele fazia uma alusão às 
medidas em que restringiam o trabalho escravo, como por exemplo, a aprovação das leis associadas ao combate ao tráfico de africanos ao Brasil.

Ainda como resultado de uma política equivocada, pautada muito mais na repressão do que no convencimento, muitos trabalhadores se refugiavam nas matas e nas terras de fronteira, em litígio com outros países. Como destacava os registros governamentais, diante da "vida opressiva e degradante a que havia se transformado os Corpos de Trabalhadores, indivíduos migravam para outras regiões, preferindo expatriar-se que sujeitar-se aos vexames a que estavam obrigados". ${ }^{4}$ Nas informações emitidas pelas autoridades da província, a emigração de parte da população do Pará se dava pelo Alto Rio Branco, pelo rio Solimões e pelo Alto Rio Negro, identificando-se alguns desertores pelas margens do lago Amapá e terras vizinhas de Caiena. ${ }^{5}$

Embora sua criação estivesse relacionada ao controle social e de prevenção de novas ações de revolta que se assemelhassem a Cabanagem da década de 1830, ou ainda como estratégia de arregimentação de mão-de-obra, ${ }^{6}$ o estabelecimento dos Corpos de Trabalhadores foi constantemente repudiado pelos discursos em defesa do trabalho livre, a exemplo da já citada fala do conselheiro Jerônimo Coelho. A adoção dessa liberdade de ação para os trabalhadores seria, nessa perspectiva, fundamental para a retomada do desenvolvimento provincial, uma vez que, as diligências para a captura de mão-de-obra estariam levando a fuga de um grande contingente de homens em condições de produzir e desenvolver a região (FULLER, 1999, p. 17).

Sobre esta questão, observa-se que a partir da década de 1850 , as ações dos Corpos de Trabalhadores passam a coexistir com um tipo de debate associado ao trabalho livre e a produtividade. Neste sentido, os projetos de colonização, pautados na imigração e no trabalho agrícola, assumem destaque nos discursos das autoridades, quando comparados as ações militarmente repressivas aos trabalhadores. É o que se observa na fala do conselheiro Sebastião do Rego Barros de 15 de agosto de 1854, em que defende a atuação do governo mais voltada a promover a produção, do que a repressão das populações que habitavam o interior da província. Ele chegava inclusive a defender a criação de medidas que "[favorecessem] a introdução de colonos, a construção de espaços de colonização para promover a agricultura e [o] povoamento, além da implantação de fazendas públicas de criação de gado para abastecimento dos centros urbanos". 7

As ações de ordenação e disciplina, postas a partir dos recrutamentos, portanto, já não eram mais compatíveis com o novo modelo de Estado que estava se consolidando 
no Brasil, e que era reproduzido no discurso do conselheiro Rego Barros. As garantias de adesão à ordem e a disciplina viriam através da difusão de valores associados à ideia de civilização, que asseguraria "o primado da Razão, o triunfo do progresso, a difusão do espírito da Associação, a formação do povo" (MATTOS, 2004, p. 271-272). Neste aspecto, a defesa de hábitos civilizados e a sua materialização através de novas percepções quanto ao trabalho e o uso de modernas técnicas produtivas, seriam os elementos necessários de aproximação do Brasil às nações civilizadas. Diante desta questão, que se pautava no processo de adoção de novos hábitos, caberia ao Estado, enquanto principal instituição promotora da modernização do país, criar estratégias de sua propagação; agora não mais se utilizando apenas de instrumentos caracterizados pelo uso da força e da coerção, a exemplo dos Corpos de Trabalhadores, mas também no emprego de um discurso de convencimento que estaria pautado na defesa da modernidade e civilização do país.

Não há dúvida que a "suplantação do termo ordem pelo da necessidade de difusão de uma civilização”. De acordo com Ilmar de Mattos (2004, p. 214-215) estas modificações estavam associadas às exigências do novo modelo de Estado que se construía no país, em que pautava as suas ações no conhecimento da população, nas criações de ações associadas à saúde pública, ao estabelecimento da regulação de diferentes profissionais e na implantação de valores, normas e padrões associados às nações civilizadas. No caso do Grão-Pará, estava associado também às estratégias de resistência as ações opressivas que caracterizavam os Corpos de Trabalhadores, como as fugas para as regiões de fronteira, por exemplo. Como foi observado, devido à impossibilidade de se exercer um controle maior sobre os trabalhadores recrutados, as autoridades provinciais procuravam desenvolver outras formas de dominação, não mais pautada no uso das forças militares. Em outras palavras, diríamos que a situação exigia outros posicionamentos em que a dominação estivesse revestida de um discurso legitimador da ordem, em que os indivíduos interiorizem esses valores sem o recurso a coações materiais. Nesse aspecto, evoca-se um pensamento de moralidade e defesa ao trabalho como instrumento capaz de livrar as populações da miséria e pauperismo. Nestes novos posicionamentos, a defesa de novos hábitos seria fundamental para a melhor condição de vida dessas populações. Assim, constrói-se um discurso em que, se por um momento responsabiliza as populações pobres pela sua própria condição de pobreza, por outro apontava para as ações do governo e o seu fiel cumprimento como capazes de superar essa condição. 
O processo de legitimação da ordem passa, portanto, pela interiorização de valores e sua assimilação por segmentos dominados da sociedade, a partir da construção de símbolos representativos. Por conseguinte, o Estado passa a ser representado simbolicamente pelos discursos construídos em torno da política de colonização agrícola na Amazônia. Neste aspecto, estamos trabalhando na perspectiva de que os elementos simbólicos construídos em torno do Estado imperial no Brasil cumprem uma função política de instrumentos de imposição e de legitimação da dominação (BOURDIEU, 2007, p. 11-13). No entanto, há de se considerar que as simbologias devem sua estrutura e as funções mais específicas, às condições sociais da sua produção e da sua circulação, ou seja, suas características mais específicas são respostas, não apenas aos interesses das classes ou das frações de classe que elas exprimem, mas também aos interesses específicos daqueles que a produzem e do campo de produção.

A partir dessas reflexões, estamos propondo um entendimento do processo de legitimação das ações do Estado imperial na Amazônia, quanto à política de colonização agrícola, como não apenas resultado da articulação dos interesses dos segmentos dominantes da sociedade local e da nação, mas também associado às condições materiais de sua produção e da sua circulação. Nesse caso, as percepções construídas sobre agricultura e o papel a que deve assumir o Estado brasileiro, em parte se deve as condições materiais das diferentes regiões do país. Estamos afirmando, portanto, que os discursos construídos em torno da atividade agrícola e a atuação do Estado neste processo, estão condicionados à formação de sistemas simbólicos que refletem os interesses de classe e os elementos que dão subsídios para sua produção.

\section{Estado imperial "às voltas" com as ordenações}

Em 29 de fevereiro de 1864, Domingos Soares Ferreira Penna (1864, p. 03), na época secretário da presidência do Pará, identificava a dificuldade em administrar as terras desta província pela falta de conhecimento dos recursos naturais que poderiam ser explorados na região, do modo de vidas das populações e da relação que os administradores estabeleciam com essas localidades. Do ponto de vista do secretário, havia a necessidade de maior contato com as povoações do interior. Esse desconhecimento, concluía, provocava a emissão de ordenações que não atendiam às condições e necessidade de cada região, fazendo com que essas populações quase sempre não atentassem para as medidas tomadas pelas autoridades. 
Na percepção de Ferreira Penna, a utilidade das legislações emitidas pelos administradores estaria associada a sua correta aplicação, sendo esta condicionada a sua eficácia quanto à resolução dos problemas, não apenas do ponto de vista do interesse do governo provincial, mas ainda das populações que residiam na província. Nesse aspecto, as ordenações aparecem como medidas que deviam manifestar-se vantajosas, não apenas para o governo que as institui, pois conforme este entendimento, a obediência às legislações estava condicionada ao seu entendimento e os benefícios que estas trariam.

Nas considerações iniciais do relatório sobre a expedição de conhecimento e exploração realizadas nos rios Tocantins e Anapú em 1863, Ferreira Penna fazia referência, portanto, a necessidade de construção de ordenações que compartilhassem interesse com os diversos grupos, inclusive as populações que se encontravam “espalhadas” pelo interior da província do Pará. Daí a necessidade de conhecimento desses grupos e de suas necessidades.

Ainda sobre a questão, a ausência de informações sobre o estado das povoações fora da capital eram objetos que não podiam ser encarados com indiferença pelos presidentes de província desde os primeiros até os últimos dias de administração. Nesse aspecto, a "falta de conhecimento dos recursos e necessidades das povoações dos interiores era a causa principal de ficar freqüentemente prejudicado o serviço público e o desenvolvimento e progresso do resto da província” (PENNA, 1864, p. 03).

Não há dúvida que as suas considerações expressavam outra dinâmica tomada pelo governo provincial, agora não apenas caracterizada pela imposição violenta das ordenações. O Estado ordenador, nessa perspectiva, deveria atuar no entendimento das necessidades das populações e também revestir essas ordenações com um discurso que justificasse essas ações como capazes de promover o desenvolvimento econômico da província e a melhoria das condições de vida da população do interior. Não é sem justificativa, que as expedições de conhecimento e exploração, a exemplo da liderada pelo próprio Ferreira Penna em 1863 e que se propunha a visitar a região margeada pelo Tocantins até a cachoeira das Guaribas e às baias do rio Anapú, tinham o propósito de identificar os produtos naturais de maior proveito e vantagem para o comércio, o estado da agricultura e os seus principais produtos, as atividades industriais desenvolvidas pelas populações, os estabelecimentos fabris e agrícolas, e o estado das povoações e as suas necessidades mais urgentes.

Não se trata, no entanto, de um discurso de tolerância às populações do interior e ao seu modo de vida, mas criar estratégias que forjassem esses grupos à aceitação das 
ordenações emitidas pelas autoridades provinciais. Torna-se evidente, como já observado anteriormente, que a criação de outras estratégias de dominação, não mais caracterizadas apenas pelo uso da força militar, mostra a ineficiência dessa estratégia e a preocupação cada vez maior das autoridades quanto à vivência das populações no interior da província.

Essa preocupação foi muito bem registrada pelo, na época ministro da Justiça, Paulino Soares de Sousa, em que apresenta as condições de moradia como elemento de maior preocupação para os governantes do Império, visto que esses indivíduos estariam "separados uns dos outros e das povoações por grandes distâncias, cobertas de matas e serras em certo estado de independência, e fora do alcance da ação do governo e das autoridades". 8 Nesse aspecto, quando há uma referência à criação de medidas governamentais que compartilhe com os interesses das populações do interior da província, isto se deve a perspectiva de que esses grupos, embora vivam em situações não condizentes com o que se propõe como hábito moderno e civilizado, deve essa condição muito mais a ausência de uma ação do governo brasileiro que os oriente e auxilie na modificação desse modo de vida (aqui fica entendido principalmente as experiências de um cultivo considerado rudimentar), do que a própria vontade desses indivíduos em se manterem, no que na época se identificava como "estágio inferior de desenvolvimento". 9 As populações que viviam em condições não condizentes com as novas ordenações, dentro desta perspectiva, buscariam naturalmente adquirir novos hábitos. Caberia, então, ao Estado assegurar a construção de ordenações que estimulassem essas novas práticas associadas à condição de modernidade e civilização.

Partindo desse princípio, foram construídas diversas legislações relativas à política de colonização agrícola, o que estava quase sempre revestida de um discurso que justificava essas ordenações pela necessidade de povoamento do solo da região, braços para o cultivo, criação de novos hábitos, importações de técnicas de plantio e manejo da terra e da floresta. A Lei $\mathrm{n}^{\circ}$. 13, de 12 de maio de 1838, por exemplo, autorizou o governo a conceber privilégio exclusivo de navegação na bacia amazônica, como necessária para o desenvolvimento da economia local, pois, ao mesmo tempo em que assegurava o transporte de mercadorias na região, facilitando o escoamento da produção agrícola e extrativa para os portos da capital do Pará, também estimularia o povoamento, conforme apontava o artigo 19 sobre o estabelecimento de colonos. ${ }^{10}$ No caso, acreditava-se que a facilitação dos transportes atraísse a construção de novas propriedades no interior da província e o aumento da produção nas já existentes, pois 
seria assegurada, a partir do desenvolvimento da navegação, a comercialização desses produtos, não colocando o proprietário em condições de risco com a perda da safra por falta de transporte.

Diante de uma legislação em que a defesa da livre navegação no rio Amazonas era justificada pela necessidade de escoamento da produção e promoção da economia local, outras ordenações se propunham a facilitar o transporte de colonos. Nesse contexto, aponta-se a criação pela Assembléia da província do Pará da Lei nº .226 , de 15 de dezembro de 1853, que estabeleceu "uma caixa especial", com fundos de 20:000\$000 anuais, prestados pelo Tesouro do Pará, órgão responsável pela arrecadação de tributos e distribuição desses recursos nas instâncias administrativas de governo, para o fim de promover e facilitar a introdução de colonos. Conforme legislação, podia a administração da província distribuí-los, mediante fiança, as particulares ou companhias que se propusessem a cumprir a lei. Em 1854, a Resolução provincial nº. 263, de 13 de outubro do mesmo ano, além de aumentar os fundos a serem gastos com a introdução de colonos para 40:000\$000, definia os tipos de imigrantes a serem transferidos ao Pará. No caso, defendia os oriundos de Portugal e da Galízia, pois estes, nas afirmações das autoridades provinciais, falavam o mesmo idioma dos brasileiros, o que facilitaria a adaptação ao novo território. ${ }^{11}$

Os propósitos dessas legislações, embora estivessem revestidos de um discurso de aumento do número de trabalhadores para atividade agrícola e os conseqüentes crescimentos da população e da produção, faziam referência apenas à introdução de colonos. Esta situação, de acordo com Palma Muniz (1916, p. 23), nos estudos sobre imigração e colonização entre os anos de 1823-1889, não correspondia à questão mais importante do problema das ações colonizadoras e em defesa da agricultura e da imigração nas províncias do Norte do Brasil. ${ }^{12}$ Para este autor, na década de 1840 , embora as proposições do Estado, materializadas nas legislações formuladas pela Assembléia do Pará e executadas pela presidência da província, estivessem ideologicamente fundamentadas em discurso em defesa da importação de braços para a lavoura, tinham os seus efeitos anulados, pois não havia uma preocupação em definir as localidades em que esses colonos seriam instalados, nem tão pouco em especificar os propósitos desses imigrantes na região. Tratava-se, de não se atentar para o elemento principal de defesa da colonização agrícola para a Amazônia, que era promover a implantação de novos hábitos junto aos colonos nacionais. 
Se em um primeiro momento as ordenações se preocupavam, em geral, em facilitar a entrada de colonos, para um momento posterior, estas estiveram voltadas para a definição de espaços que abrigariam esses colonos. A terra, pelo qual devia advir a fixação desses trabalhadores, passa a ser o principal elemento de justificativa das ordenações associadas à criação de locais para abrigo dos imigrantes que se dirigissem ou fossem conduzidos para a região. Neste aspecto, foram criadas as colônias militares, pensando a sua localização para as regiões limítrofes com outras nações e em localidades próximas as áreas consideradas "de ameaça a ordem pública”. No caso, as regiões em que se registrava a presença de negros foragidos, soldados desertores e criminosos. A justificativa para criação desses espaços consistia, portanto, na manutenção da ordem pública, segurança da população e manutenção da soberania do território nacional.

A criação de espaços especificamente construídos para recebimento desses novos colonos gerou legislações para a implantação de colônias agrícolas públicas e particulares. Nesse caso, as ordenações estavam legitimadas pela necessidade de desenvolvimento de novas técnicas de cultivo e abastecimento dos centros urbanos, o que justificava a implantação desses espaços nas proximidades dos núcleos de população, tendo por preferência, na sua ocupação, os colonos europeus. Nesse contexto, podemos citar a Lei geral $\mathrm{n}^{\mathrm{o}}$. 601, de 18 de setembro de 1850, no artigo 18, que autorizava o governo a mandar vir anualmente, a custa do tesouro público, certo número de colonos livres, para serem empregados, pelo tempo que fosse determinado, em estabelecimentos agrícolas, nos trabalhos dirigidos pela administração pública, ou na formação de colônias nos lugares em que estas fossem consideradas mais convenientes (MUNIZ, 1916, p. 29).

As legislações que são construídas apontam, portanto, para um Estado ordenador, que conforme analisado, se revestiria de um discurso em que às ordens perdiam um caráter impositivo e violento, assumindo, embora somente em nível muito mais de oratória, uma condição de bem comum, de interesse coletivo, ou de uma vontade compartilhada. A ação do Estado, nesse aspecto, é então revestida de um discurso civilizador, que camufla o seu caráter impositivo, autoritário e centralizador. Nesse caso, a atribuição de civilizador vai ser dada ao Estado imperial, na época sob a direção Saquarema, ${ }^{13}$ como necessária para a modernização e progresso do país. Civilizar para os construtores da nação, ${ }^{14}$ significava generalizar o princípio da ordem. Daí a necessidade de interpretação do Ato Adicional, em 1840, a reforma do Código do 
Processo Criminal e a Lei do Conselho de Estado, em 1841, como ações que podiam está trazendo a nação brasileira para o caminho da ordem, do progresso e da civilização. $^{15}$

Diante destas questões, estamos afirmando que, para além de uma estrutura burocrática, solidamente institucionalizada e construída por funcionários postos à margem de qualquer influência particularista, como defendiam os construtores do Estado imperial no Brasil, o Estado é, também, um espaço de ação e de concorrência permeável aos conflitos de valores e normas que perpassam a sociedade. Contudo, o grau de permeabilidade, os mecanismos de influência recíproca e, principalmente, a legitimidade desses intercâmbios entre Estado e a sociedade variam de acordo com as condições materiais em que essa relação é estabelecida (DÉLOYE, 1999, p. 68). O que estamos afirmando, em outros termos, é que, para além dos projetos de construção do Estado imperial no Brasil está às condições materiais para esta construção, o que perpassa pelas necessidades e interesses defendidos nas diferentes regiões do país. O desafio é associar esses diferentes e divergentes interesses.

No caso das províncias do Pará e Amazonas, a ação civilizatória do Estado imperial se refletiu, portanto, na criação de um programa de colonização que devia se caracterizar pelo desenvolvimento de medidas que facilitassem a introdução de colonos, promovesse a agricultura mercantil, protegessem áreas de fronteira e criassem colônias para recebimento de trabalhadores que migrassem para a região. Acrescenta-se ainda a instituição de medidas que promovessem a catequese e civilização dos índios e aproveitasse o trabalho desses indivíduos. Quanto a esta última questão é retomada a defesa da criação de missões religiosas, que promovessem junto às comunidades indígenas, a imposição de hábitos que trouxessem os índios ao que, utilizando uma expressão de época, chamavam de "grêmio da civilização". ${ }^{16}$ Estas ações estavam, no entanto, associadas a um discurso de melhoria das condições de vida e segurança das populações da Amazônia. Neste aspecto, a necessidade de desenvolvimento de outras técnicas de cultivo que promovessem as atividades agrícolas e assegurassem o melhor aproveitamento dos recursos naturais, uma das principais justificativas para implantação dos programas de colonização agrícola, se justificaria, de acordo com os discursos das autoridades, no melhor rendimento econômico da província e seria ainda acompanhado de condições de vida mais prósperas dos colonos nacionais.

A formulação desses discursos está posicionada, portanto, no processo de construção do Estado brasileiro. Nesse aspecto, a ideia de ordem estava estritamente 
associada à centralização política e administrativa, sendo que este tema tinha uma relação pontual com a organização do poder do Estado e a legitimação de seus interesses nas províncias. Na defesa da centralização das ações políticas, se percebia a condição necessária para manter, não somente o que se considerava como ordem social, evitando as revoltas presenciadas no país alguns anos antes, a exemplo da Cabanagem no Pará, e que marcaram a administração regencial. Acrescenta-se também, a necessidade de manter a Monarquia e a unidade física do território, pois a centralização era condição indispensável para existência do Império do Brasil e para ligação entre o Sul e o Norte do país, caracterizadas como regiões de dessemelhanças "nos climas, territórios, espírito, interesses, comércio, produtos e estado social” (URUGUAI, 2002, p. 439).

É neste contexto que os construtores da nação percebem o Norte do país. Por um lado, como espaço a ser mantido sob o controle da Corte no Rio de Janeiro, assegurando a configuração de um Estado imperial com um vasto território. Nesse aspecto, as colônias militares tinham um papel importante, pois, se propunha assegurar a soberania territorial. Por outro, o Norte poderia fortalecer a economia nacional, através da promoção da agricultura, com a criação de colônias agrícolas, conforme apontava o ministro dos Negócios Império Francisco Gonçalves Martins, em 1853. ${ }^{17}$ Esta situação foi também observada por Evaldo Cabral de Melo (1984, p. 12-13) nos seus estudos sobre "O Norte Agrário e o Império", em que fazia referência aos "vastos horizontes da Amazônia" - ao usar a expressão do deputado paraense Mancio Ribeiro, em 1888 como espaço a ser assegurado o domínio, com a promoção do povoamento e da economia nacional, esta última concebida com o aumento das forças produtivas agrícolas nesta região. Como se observa, as ações do Estado, em defesa da agricultura e colonização, se propunham a superar a concepção construída do Norte do Brasil de "feitoria do Sul", usando aqui a expressão de um senhor de engenho da província de Pernambuco e citado por Evaldo Cabral de Melo. De acordo com o ministro dos Negócios do Império em 1851, José da Costa Carvalho, o visconde de Monte Alegre, a ação do governo imperial nas províncias, não se tratava apenas do exercício do controle político, mas, assegurar a prosperidade econômica dessas regiões de forma a influenciar no fortalecimento da economia do país e nos cofres públicos, gerando assim, novos investimentos. $^{18}$

Nas considerações de Ilmar de Mattos (1999, p. 206-207), a perspectiva de intervenção do governo imperial nas províncias, a exemplo da criação de medidas de 
fortalecimento da atividade agrícola na Amazônia, como apontamos, estava associada à construção de ordenações a serem executadas pelas administrações locais. A ordem era a condição para a existência da liberdade e para a construção de hábitos civilizados e modernos. No caso, tratava-se de uma ordem caracterizada por uma dimensão política, pois, devia organizar as ações do Estado, e também de dimensão social, o que não ocorreria naturalmente, mas como resultado da ação coordenada e da expansão da capacidade reguladora da administração pública, que se materializaria por meio da criação de um aparato administrativo subordinado a um mesmo comando. Esta concepção de ordem, que diríamos, estava marcada pela centralização, resultava, ainda, em grande parte, da consideração das "circunstâncias do país, dos hábitos, da dispersão da população", "da dificuldade de comunicação", "do pequeno número de homens habilitados para a gerência dos negócios nas localidades" e "da pequena integração econômica entre as províncias" (URUGUAI, 2002, p. 495).

Tal situação levava ao reconhecimento de que a promoção de políticas modernizadoras para o país necessariamente estava condicionada a uma ação centralizadora, uma vez que as regiões do Brasil se encontravam em estágio e níveis de desenvolvimento diversificados. Esta situação passa a justificar uma ação de abandono do modelo de outras experiências políticas, principalmente aquelas descentralizadoras, inspiradas no modelo inglês e norte-americano. Assim, a construção do Brasil enquanto nação soberana e moderna estava condicionada ao desenvolvimento econômico, senão homogêneo, pelo menos semelhantes, nas diferentes regiões do país. Em outras palavras, não era concebível pensar o Brasil moderno e territorialmente integrado se as regiões se mantivessem economicamente desiguais e desarmônicas na sua produção. ${ }^{19}$

As províncias do Pará e Amazonas, nesse caso, caracterizadas como predominantemente extrativas, deviam então pautar as suas ações na promoção de uma política de valorização da agricultura, pois isto aproximaria, de acordo com os interesses das autoridades imperiais, com as províncias do Sudeste, fortalecendo a economia do país e das próprias províncias. Como dizia o ministro da Agricultura em 1853, havia a necessidade de transplantar para os campos férteis das províncias do Norte "práticas mais vantajosas". ${ }^{20}$ No caso, defendia a substituição de uma prática econômica caracterizada pelo extrativismo por práticas agrícola, apontadas como capazes de assegurar uma permanente produção, domínio sobre as técnicas produtivas e a conseqüente independência quanto às forças da natureza. Esta situação possibilitava ainda a construção de propriedades agrárias com a fixação do homem à terra. 
O desenvolvimento das forças produtivas no Norte do Brasil, nos dizeres do ministro dos Negócios da Justiça Paulino José Soares de Sousa, estava condicionado à promoção de medidas de fortalecimento da atividade agrícola, sendo acompanhada de ações de combate, sobretudo da desordem civil. Nesse aspecto, o alvo principal dessas ações era as populações pobres, consideradas bárbaras e incultas, e grupos dominantes locais que forjavam o poder em defesa de interesses pessoais. Assim, cabia ao Estado, através de suas ordenações, o combate à ociosidade de parte da população que estava embrenhada nas matas brasileiras. O remédio proposto era o aperfeiçoamento da polícia e da justiça. Como observado, este combate ao modo de vida das populações rurais era revestido de um discurso legitimador da ordem como necessária à promoção da modernidade e civilização do país e a conseqüente melhoria nas condições de vida dessas populações. No caso da desordem entre os grupos dominantes, outro tratamento era sugerido, pois, não era reflexo da ausência de hábitos civilizados, o que não exigia uma organização policial e da justiça, mas sim uma organização política e administrativa capaz de conciliar diferentes interesses. Nas palavras do então ministro dos Negócios da Justiça "era preciso adotar uma política larga que fazendo calar as vozes mesquinhas das influências locais, e de interesses particulares, desse lugar a que somente pudesse ser ouvida a da razão nacional, única e verdadeira indicadora do pensamento e necessidades públicas". ${ }^{21}$ Nestas circunstâncias, o Estado se afirmaria enquanto instância maior de garantia da liberdade contra o arbítrio do poder particular, dos grupos que forjavam o poder nas localidades e submetiam as populações ao seu controle e domínio. O poder do Estado podia, assim, ser um elemento de ordem e civilização, de garantia de direitos por meio da aplicação de uma justiça independente dos poderes locais e do arbítrio das lutas políticas das localidades. As ações de fortalecimento da economia nas províncias do Norte do Brasil se revestiriam, portanto, de uma oratória associada à promoção de hábitos civilizados, domínio sobre as forças da natureza e desenvolvimento das forças produtivas agrícolas, circunscritas a um Estado mantenedor da ordem.

A necessidade de promoção da economia local associada à ideia de manutenção da ordem, defesa de hábitos civilizados e desenvolvimento de novas técnicas de produção, resolvia, em parte, aquilo que José Roberto de Arruda Machado (2007, p. 115) chamava de "difícil tarefa de acomodar a província do Grão-Pará ao Império do Brasil". No caso, este fazia referência às tensões resultantes das intervenções do governo central no cotidiano da província do Pará, desde a chegada do primeiro 
presidente nomeado pelo Rio de Janeiro, em 1824, pois se rompia o breve ciclo, iniciado com a adesão de Belém às Cortes de Lisboa, no qual os paraenses gozaram a possibilidade de eleger o governo da província autonomamente. ${ }^{22}$ A partir de então, essa decisão passava a estar condicionada a uma política exógena que os grupos locais precisaram aprender a manejar. Esta situação, segundo Ilmar Mattos (2005) marcava a década de 1820, pós-independência, e décadas posteriores, de 1830 e 1840, como momento de dificuldades de integração das províncias ao sistema de governo defendido a partir do Rio de Janeiro, num movimento que chamou de "expansão para dentro".

As tensões envolvendo o governo imperial e as autoridades provinciais na Amazônia podem ser ilustradas no golpe sofrido pelo visconde de Goiana, nomeado em 29 de julho de 1831, presidente do Grão-Pará; governo que não durou vinte dias. O golpe que causou a sua deposição foi motivado pela reação, de parte dos setores dominantes locais, ao empenho do presidente em fazer cumprir em território grãoparaense um decreto imperial que extinguia os cargos de governadores militares dos distritos. A ação causou descontentamento por que a estrutura militar que o visconde de Goiana tentava desmantelar era fundamentalmente importante para o recrutamento compulsório de mão-de-obra de índios destribalizados que viviam espalhados nas aldeias, povoados e cidades, e que eram aproveitados como fonte de braços para os proprietários de terra na região. ${ }^{23}$

As reações locais frente às ordenações do governo imperial exigiam melhores articulações com as forças políticas na província, o que em parte, responde a preocupação de Ferreira Penna de que as legislações precisariam ser construídas, levando em consideração os interesses dos administradores e das populações atingidas, em uma perspectiva de atendimento das necessidades desses grupos e de convencimento ao cumprimento dessas legislações. Era preciso, portanto, encontrar uma questão que mobilizasse as forças políticas locais e nacionais em direções convergentes. Ao que se observa, a defesa do melhoramento da agricultura é a ação que aproxima os interesses provinciais e do Império. 


\section{Notas}

${ }^{1}$ PARÁ. Falla dirigida pelo Exmo. Sr. Conselheiro Jerônimo Francisco Coelho, Presidente da Província do Gram-Pará a Assembléia Legislativa Provincial na abertura da segunda sessão ordinária da sexta legislatura no dia $1^{\circ}$ de outubro de 1849. Pará, Typographia de Santos \& Filhos, 1849, p. 22.

${ }^{2}$ Idem, p. 22.

${ }^{3}$ PARÁ. Falla dirigida pelo Exmo Sr. conselheiro Jeronimo Francisco Coelho, presidente da província do Gram-Pará, á Assembléia Legislativa Provincial na abertura da sessão ordinária da sexta legislatura no dia 1.o de outubro de 1848. Pará, Typ. de Santos \& filhos, 1848, p. 23.

${ }^{4}$ Conforme registro da administração provincial do Grão-Pará, os Corpos de Trabalhadores estariam atuando na capital da província, Belém, em Cametá, Vigia, Santarém, Macapá, Bragança, Gurupá, Marajó e no Rio Negro, sendo que estava ao todo composto por 71 oficiais, 141 oficiais inferiores, 7.444 trabalhadores recrutados. Os lugares Macapá, Marajó e Rio Negro registravam um número maior, tendo 1.253, 1.594 e 1.885 trabalhadores respectivamente. In: PARÁ. Falla dirigida pelo Exmo. Sr. Conselheiro Jerônimo Francisco Coelho, Presidente da Província do Gram-Pará a Assembléia Legislativa Provincial na abertura da segunda sessão ordinária da sexta legislatura no dia $1^{\circ}$ de outubro de 1849. Pará, Typographia de Santos \& Filhos, 1849, p. 21.

${ }^{5}$ PARÁ. Falla dirigida pelo Exmo Sr. conselheiro Jeronimo Francisco Coelho, presidente da província do Gram-Pará, á Assembléia Legislativa Provincial na abertura da sessão ordinária da sexta legislatura no dia 1.o de outubro de 1848. Pará, Typ. de Santos \& filhos, 1848, p. 33.

${ }^{6}$ Os Corpos de Trabalhadores foram compreendidos pela historiografia como instrumento de dominação de grupos sociais a exemplo de trabalhadores livres e índios, de aprisionamento de mão-de-obra, combate a possíveis focos de revolta e ainda a imposição de valores e disciplinarização. Sobre a questão ver os trabalhos: DI PAOLO, 1985; FULLER, 1999; MOREIRA NETO, 1992; RAIOL, 1970; RICCI, 1993, p. 13-28; SALLES, 1988, p. 262-295; SILVEIRA, 1994; e WEINSTEIN, 1993.

${ }^{7}$ PARÁ. Falla que o Exmo Snr. Conselheiro Sebastião do Rego Barros, presidente desta Província dirigiu à Assembléia Legislativa Provincial na abertura da mesma Assembléia no dia 15 de agosto de 1854. Pará, Typ. da Aurora Paraense, Imp. Por J. F. de Mendonça, 1854, p. 34.

${ }^{8}$ BRASIL. Relatório da Repartição dos Negócios da Justiça do anno de 1840 apresentado a Assembléia Geral Legislativa, na sessão ordinária de 1841, pelo Ministro e Secretário de Estado Paulino José Soares de Sousa. Rio de Janeiro: Typographia Nacional, 1841, p. 3-4.

${ }^{9}$ Costumeiramente se utiliza esta expressão para identificar o modo de vida das populações do interior das províncias da Amazônia, sendo que por "estágio inferior de desenvolvimento" associa-se a atividade extrativista comum nas comunidades da Amazônia. Nesse caso, a agricultura adotada por essas comunidades, em detrimento da extração, posicionaria esses grupos em condições de maior desenvolvimento da economia e domínio de novas técnicas de produção, que os tornassem mais independentes das forças da natureza. Para uma leitura sobre a relação entre a agricultura e exercício de domínio das matas e conseqüente estágio maior de desenvolvimento da produção ver os trabalhos de: LOURENÇO, 2001; LINHARES \& SILVA, 1981; CARMO, 1908; e SMITH, 1947.

${ }^{10}$ PARÁ. Exposição apresentada pelo Exmo. Sr. Conselheiro Sebastião do Rego Barros, Presidente da Província do Grão-Pará, por ocasião de passar a administração da mesma Província ao $1^{o}$ VicePresidente o Exmo. Sr. Dr. Ângelo Custódio Corrêa em 14 de maio de 1855. Pará, Typographia de Santos \& Filhos, 1855, Anexos e Mapas, p. 1-3.

${ }^{11}$ Para o presidente do Pará, Conselheiro Sebastião do Rego Barros, muito mais do que facilitar a introdução de colonos na região, deveria se atentar para as condições de permanência desses grupos, criando as condições necessárias para recebimento e acomodação e identificando junto às populações da Europa, as que melhor se adaptaram as condições apresentadas pela província. In: PARÁ. Exposição apresentada pelo Exmo. Sr. Conselheiro Sebastião do Rego Barros, Presidente da Província do GrãoPará, por ocasião de passar a administração da mesma Província ao $1^{\circ}$ Vice-Presidente o Exmo. Sr. Dr. Ângelo Custódio Corrêa em 14 de maio de 1855. Pará, Typographia de Santos \& Filhos, 1855, p. 7-8).

12 Durante o Império, a geografia regional do Brasil reduzia-se, na linguagem oficial, a diferenciação entre Norte e Sul, compreendendo o primeiro as províncias situadas do Amazonas à Bahia, e o segundo ao território entre as províncias do Espírito Santo e do Rio Grande (VAINFAS, 2008, p. 39). Neste trabalho, no entanto, recorreremos ao uso das expressões Norte do Império ou Norte do Brasil, como a região correspondente as províncias do Pará e suas comarcas subordinadas, de onde se desmembrou a província do Amazonas, em 1850.

${ }^{13}$ Para Ilmar de Mattos (2004, p. 119-120), o termo Saquarema não podia deixar de está relacionado à maneira como se apresentava as forças constitutivas do Partido Conservador. Constituídos, em grande parte, por conservadores fluminenses, tendiam a se apresentar organizados e dirigidos pela "trindade 
saquarema": Rodrigues Torre, futuro visconde de Itaboraí, Paulino José de Souza, futuro visconde do Uruguai e Eusébio de Queiroz.

${ }^{14}$ Expressão utilizada para identificar os que forjavam uma unidade na constituição do Estado imperial, através de valores, signos e símbolos imperiais (MATTOS, 2005, p. 26).

${ }^{15}$ Para exemplificar esse processo centralizador, Eliza Mader (2006, p. 25) destaca o caso do Ato Adicional, aprovado em agosto de 1834, que reformava a constituição de 1824 . Por esta nova lei, aboliuse o Conselho de Estado, estabeleceu-se a Regência Una eletiva e temporária, e criaram as assembleias legislativas nas províncias com amplas atribuições. Os anos que se seguiram à promulgação do Ato Adicional foram marcados por ameaças à unidade nacional pretendida pela Corte do Rio de Janeiro. Entre 1835 e 1838, varias rebeliões eclodiram em diferentes províncias, como a Cabanagem no Pará, a Sabinada na Bahia, a Balaiada no Maranhão, e a Farroupilha no Rio Grande do Sul. Assim, o Ato Adicional provocou um rearranjo das forças partidárias em torno da questão da descentralização e de seus efeitos. Os "regressistas", diante dessa situação, levantaram a bandeira da necessidade de revisão de estrutura institucional, visando o restabelecimento da autoridade e da ordem. A partir daí, abriu-se um caminho que levou, em meados do século XIX, uma estrutura política e administrativa bastante centralizadora, compartilhando ainda para isso, a reformulação do Código do Processo Criminal e a Lei do Conselho de Estado, ambos na década de 1840.

${ }^{16}$ Para o conselheiro João Antonio de Miranda, defensor da reorganização das ações missionárias na Amazônia, esta devia se caracterizar com a primeira via de contato com a população indígena de forma a aproveitar esta mão-de-obra na atividade extrativa e agrícola, sendo que para isso era necessário incutir nesses grupos novos valores, principalmente a produzir para a comercialização (DPPP, 15/08/1840, p. $60)$.

${ }^{17}$ BRASIL. Relatório do anno de 1852 apresentado a Assembléia Geral Legislativa na $1^{a}$ Sessão da $9^{a}$ Legislatura pelo Ministro e Secretário de Estado dos Negócios do Império Francisco Gonçalves Martins. Rio de Janeiro, Typographia Nacional, 1853, p. 36-37.

${ }^{18}$ No caso das províncias do Norte defende como ação imediata de fortalecimento da economia local, investimento nas colônias de São João do Araguaia, vila de Macapá e Alto Rio Branco, no Pará; e estudos para criação de espaços de colonização agrícola em Leopoldina e Santa Isabel, margem do rio Araguaia e na extremidade sul da Ilha do Bananal, na província de Goiás. In: BRASIL. Relatório do anno de 1851 apresentado a Assembléia Geral Legislativa na $4^{a}$ Sessão da $8^{a}$ Legislatura pelo Ministro e Secretário de Estado dos Negócios do Império José da Costa Carvalho. Rio de Janeiro, Typographia Nacional, 1852, p. 23).

${ }^{19}$ A integração econômica das províncias do Brasil não foi defendida apenas pelos "construtores da nação", a exemplo do visconde de Uruguai. Esta defesa veio também de alguns liberais, como Aureliano Cândido Tavares Bastos. Embora defendesse a descentralização política como fundamental para a autonomia das províncias e o seu consequiente crescimento econômico, pois daria maior agilidade à máquina administrativa provincial, libertando-as do peso e da lentidão da burocracia da Corte, e ainda do caráter absolutista que a centralização do Rio de Janeiro representava, esta descentralização ao mesmo tempo em que valorizava os interesses da província, não podia causar prejuízo em outras regiões. Nesse caso, a idéia era que os interesses gerais nas províncias, no caso o interesse do Estado imperial, ao mesmo tempo em que assegurasse os interesses de determinada província, não devia permitir que outras províncias fossem lesadas. É o que podíamos chamar de um Estado regulador, ajustador, administrador; em substituição ao Estado controlador, dominador dos interesses das províncias do Brasil (BASTOS, 1976, p. 46-47; 1975, p. 228-229; 1938, p. 60).

${ }^{20}$ BRASIL. Relatório do anno de 1852 apresentado a Assembléia Geral Legislativa na $1^{a}$ Sessão da $9^{a}$ Legislatura pelo Ministro e Secretário de Estado dos Negócios do Império Francisco Gonçalves Martins. Rio de Janeiro, Typographia Nacional, 1853, p. 30.

${ }^{21}$ BRASIL. Relatório da Repartição dos Negócios da Justiça do anno de 1842 apresentado a Assembléia Geral Legislativa, na $1^{a}$ Sessão da $5^{a}$ Legislatura, pelo Ministro e Secretário de Estado Paulino José Soares de Sousa. Rio de Janeiro: Typographia Nacional, 1843, p. 3.

${ }^{22}$ De acordo com Adilson Brito (2008, p. 116), o processo de independência do Brasil teria como marco cronológico inicial o $1^{\circ}$ de janeiro de 1821 , pois teria desencadeado uma série de acontecimentos que acabariam por produzir a ruptura com a metrópole e o estabelecimento das fundações do Estado-Nação brasileiro. A deposição da Junta Interina de Sucessão do Grão-Pará e a eleição da primeira Junta Provisória de Governo em substituição aos antigos cargos de capitães-generais seriam, nessa perspectiva, não apenas acontecimentos que desencadeariam o processo de independência, mas teria possibilitado a província de eleger os seus governadores.

${ }^{23}$ De acordo com André Roberto de Arruda Machado (2007, p. 116), as legislações sobre as populações nativas advindas do período pombalino estabeleciam que esses indígenas podiam ser obrigados ao 
trabalho compulsório em obras públicas e particulares, ao mesmo tempo em que passavam a ser considerados como súditos do rei de Portugal, sem qualquer tutela. Logo após a independência, o GrãoPará foi envolvido numa guerra civil motivada pela tentativa dos indígenas destribalizados, em sua maioria, de minarem as estruturas que garantiam a exploração compulsória de sua mão-de-obra. Fracassada essa tentativa de mudança e permanecendo o trabalho compulsório indígena como principal mão-de-obra da província, esse movimento poderia ter desvelado aspecto da fragilidade dos instrumentos de dominação na região, combatido pelas ações de revolta na Cabanagem. Sobre a guerra civil dos anos de 1823 e 1824, ver: MACHADO, 2005 e 2006. Ainda sobre estes conflitos, numa outra perspectiva: COELHO, 1978.

\section{Referências Bibliográficas}

BASTOS, Aureliano Cândido Tavares. Os males do presente e as esperanças do futuro: estudos brasileiros. São Paulo: Ed. Nacional, 1976.

BASTOS, Aureliano Cândido Tavares. A Província: estudo sobre a descentralização no Brasil. São Paulo: Ed. Nacional, 1975.

Cartas do Solitário. São Paulo: Companhia Editora Nacional, 1938 [1862].

BOURDIEU, Pierre. O poder simbólico. Rio de Janeiro; Bertrand Brasil, 2007.

BRITO, Adilson Júnior Ishihara. "Viva a Liberte": cultura politica popular, revolução e sentimento patriótico na independência do Grão-Pará, 1790-1824. Dissertação de Mestrado em História, CFCH - UFPE, Recife, 2008.

CARMO, A. G. do. O Estado Moderno e a Agricultura. Rio de Janeiro: Imprensa Nacional, 1908.

COELHO, Geraldo Mártires. Ação e reação na província do Grão-Pará: o conflito político-social de 1823. Dissertação de Mestrado em História, ICHF-UFF, Niterói, 1978.

DI PAOLO, Pasquale. Cabanagem: a revolução popular da Amazônia. Belém: CEJUP, 1985.

FULLER, Claudia Maria. Os Corpos de Trabalhadores: política de controle social no Grão-Pará. Fascículo LH. Laboratório e Departamento de História CFCH, UFPA, Belém, no. 01, 1999, p. 01-17.

LINHARES, Maria Yedda; SILVA, Francisco Carlos Teixeira da. História da Agricultura Brasileira. São Paulo: Brasiliense, 1981.

LOURENÇO, Fernando Antonio. Agricultura Ilustrada e escravismo nas origens da questão agrária brasileira. Campinas, SP: Editora da Unicamp, 2001.

MACHADO, André Roberto de Arruda. A difícil tarefa de acomodar a província do Grão-Pará ao Império do Brasil: a atuação dos representantes paraenses no Parlamento do Império do Brasil: 1826-40. In: Almanaque Braziliense, 2007, n.6, p. 115-120.

MACHADO, André Roberto de Arruda. A quebra da mola real das sociedades. A crise política do Antigo Regime português na província do Grão-Pará (1821-25). Tese de Doutorado, FFLCH, Universidade de São Paulo, São Paulo, 2006.

. Em guerra, pela pretensão de "inventar" o Estado Brasileiro do Grão-Pará: 1823 e 1824. Edição Complementar dos Anais do XXIII Simpósio Nacional de História. Londrina: ANPUH, 2005, p. 1-15.

MADER, Maria Elisa Noronha de Sá. Civilização e Barbárie: a representação da nação nos textos de Sarmiento e do Visconde do Uruguai. Tese de Doutorado em História Social, ICHF-UFF, Niterói, 2006.

MATTOS, Ilmar Rohloff de. Construtores e Herdeiros: a trama dos interesses na Construção da Unidade Política. In: Revista Almanack Brasiliense, $\mathrm{n}^{\circ}$. 01, maio de 2005, p. 8-26. 
. "Do Império do Brasil ao Império do Brasil". In: Estudos em Homenagem a Luís Antonio de Oliveira Ramos. Porto: Faculdade de Letras da Universidade do Porto, 2004, p. 727-736.

- "O Lavrador e o Construtor: O Visconde do Uruguai e a Construção do Estado Imperial”. In: PRADO, Maria Emília (org.). O Estado como vocação. Idéias e práticas políticas no Brasil oitocentista. Rio de Janeiro: Acess Editora, 1999.

MELO, Evaldo Cabral. O Norte Agrário e o Império: 1871-1889. Rio de Janeiro: Nova Fronteira, 1984.

MOREIRA NETO, Carlos de Araújo. Igreja e Cabanagem (1832-1849). In: HOORNAERT, E. História da Igreja na Amazônia. Petrópolis: Vozes, 1992, p. 262295.

MUNIZ, Palma. Imigração e Colonisação: História e Estatística (1616-1916). Belém: Imprensa Oficial do Estado do Pará, 1916.

PENNA, Domingos Soares Ferreira. O Tocantins e o Anapú. Relatório do Secretário da Província do Pará. Belém, Typ. de Frederico Rhossard, 1864.

RAIOL, Domingos Antonio. Motins Políticos - ou a história dos principais acontecimentos políticos da Província do Pará desde o ano de 1821 até 1835. (3 vols.) Belém: Universidade Federal do Pará, 1970.

RICCI, Magda Maria de Oliveira. História Amotinada: Memórias da Cabanagem. Cadernos do Centro de Filosofia e Ciências Humanas. Belém: UFPA, vol. 12, n. 1⁄2, 1993, p. 13-28.

SALLES, Vicente. O negro no Pará: sob o regime da escravidão. Brasília/Belém: Ministério da Cultura/Secretaria de Estado da Cultura/Fundação Cultural do Pará "Tancredo Neves", 1988.

SILVEIRA, Ítala B. Cabanagem: uma luta perdida. Belém: Secretaria de Estado da Cultura, 1994.

SMITH, T. L. Sistemas agrícolas. In: Revista Brasileira de Geografia. Rio de Janeiro, ano IX, número dois, abril - junho, 1947, p. 159-178.

URUGUAI, Visconde do. "Ensaio sobre Direito Administrativo". In: CARVALHO, José Murilo de (org.). Visconde do Uruguai. São Paulo: Editora 34, 2002.

VAINFAS. Ronaldo. Francisco de Adolfo de Varnhagen. In: VAINFAS. Ronaldo (organizador). Dicionário do Brasil Imperial (1822-1889). Rio de Janeiro: Objetiva, 2008, p. 285-286.

WEINSTEIN, Bárbara. A borracha na Amazônia: expansão e decadência. São Paulo: Hucitec, 1993. 